\title{
Decentralized Control Architecture for Microgrids
}

\author{
Shailendra Kumar Ray ${ }^{1}$, and Krishna Tomar ${ }^{2}$ \\ ${ }^{1} \mathrm{M}$. Tech Scholar, Department of Electrical Engineering, RIMT University, Gobindgarh, Punjab, India \\ ${ }^{2}$ Assistant Professor, Department of Electrical Engineering, RIMT University, Gobindgarh, Punjab, India \\ Correspondence should be addressed to Shailendra Kumar Ray; shahilray30@gmail.com
}

Copyright () 2022 Made Shailendra Kumar Ray et al. This is an open-access article distributed under the Creative Commons Attribution License, which permits unrestricted use, distribution, and reproduction in any medium, provided the original work is properly cited.

\begin{abstract}
Since its establishment in the late 1800s, the electrical infrastructure has continued to grow at a steady rate for the past 100 years. Due to the increasing dependence on electrical energy, this infrastructure will be in greater demand. Infrastructures are at their limit, and equipment must be upgraded on a regular basis. As an example, if the power lines were adequate for domestic and commercial loads, but the adoption of electric vehicles continues to grow, an upgrade might not be feasible. A better alternative is the micro grid concept, or localized generation and consumption. However, because the generation sources are dispersed, controlling them and coordinating them becomes extremely difficult. Micro grid architectures with localized control are proposed as a solution to this problem. Here's a micro grid setup with separate sources integrated on a common DC bus, as well as battery storage and power monitoring and protection systems in-built.
\end{abstract}

KEYWORDS- PV, micro grid, SPWM, and relay

\section{INTRODUCTION}

Due to the increasing demand for electricity, the existing infrastructure will eventually be unable to meet it. Solar photovoltaic (SPV), wind turbines (WT), diesel generators (DGs), or even electric vehicles (EV) used as a battery source are being installed in the classical grid infrastructure to avoid this condition. This creates the problem of coordinating and regulating all of these sources. As modern relay systems are highly synchronized and monitored in operation using GPS clock systems to coordinate tasks, implementing that for distributed sources will prove to be extremely challenging. Use standard equipment and standard practices to create an independent control system at the distributed sources to combat this situation. Because of the rapid adoption of distributed renewable energy sources, such as solar photovoltaics (SPV) and solar thermal electricity, microgrids are the next best alternative for future grid modifications. A simple multi-source system is described in this paper, along with a distributed control scheme that allows each unit source to respond on its own, according to the author. As part of this process, a simulation is run in MATLAB using Simulink to construct the system, which is then studied. Any deviations, if any, are explained.

\section{OBJECTIVE}

With the help of simulation, this paper will explain the advantages of a micro-grid system with decentralized control. A DC-to-AC converter is used to convert the system's variable load into AC power using Simulink. The system's data is analyzed.

\section{LITERATURE REVIEW}

As a result of the COVID-19 pandemic and the increased use of electronic devices for remote work, the global demand for electricity is expected to increase by 30 percent by 2030 , in comparison to 2012 . As a result, the actual demand may be a little higher than anticipated.. Population growth and economic growth drive the base demand curve upward and downward, respectively. [1-2]. As of mid2020, the International Energy Agency estimates that energy investments will reach $\$ 40$ trillion.

But unlike in the past, energy is no longer exclusively produced in large power plants [4]. Power generation models are changing as a result of new global standards and agreements, and these changes are creating new opportunities. As a result, renewable energy will become a major part of the electricity market. Using dispersion to solve reliability and fail-safety problems consumers and producers $[5,6]$. An ecosystem called a microgrid (MG) is capable of providing such decentralized energy generation resources.

They can be defined in many different ways. Most experts agree, however, that microgrids can be composed of three basic components: production and demand management systems, well-defined boundaries, and island capacity [7, 8]. Depending on the source of energy, decentralized power generation can be either renewable energy or conventional energy. Although the microgrid is primarily electric, it can also contain thermal components for heating. The demand is close to these generation points, so there are limits to the amount of energy that can be produced. The system is much smaller than the main network, which is a major benefit. "Island" mode refers to a microgrid that operates independently of a larger grid, is connected to that grid, or is isolated from it [9-12].

\section{METHODOLOGY TO BE USED}

In Simulink, the microgrid structure is designed, and its performance and implementation are simulated. Analyzing 
the data collected, a conclusion is drawn about the system's performance.

\section{IMPLEMENTATION}

The setup consists of the following components:

A storage battery is one of the three sources. Loads on the DC bus and inverter AC side are two different types of loads. A three-phase power is generated by the inverter, which is used to power multiple switching loads. Using individual breakers, each with its own processing for faults and malfunction conditions, the sources are connected to common power lines. As well as at the source and after the inverter, faults are simulated at two different locations.

The use of solar photovoltaic cells is increasing. A semiconductor device, it converts incident radiation into electricity through the use of semiconductors. In the case of solar photovoltaic's (SPVs), the source is solar radiation. They are therefore designed to perform better in bands around $540 \mathrm{~nm}$, which is almost in the middle of visible spectrum radiation that reaches the Earth's surface (Yellow-Green color boundary).

- The operation of a photocell involves the following steps:

- The absorption of light and the generation of electron hole pairs.

- It is important to keep charge carriers that are incompatible separate.

- Using wires, remove the charge carriers from the battery and connect them to the external circuit.

It is possible to combine several individual cells to form a module with a protective transparent front and solid back. These housings protect the cells from damage or decay caused by ultraviolet radiation, which causes microscopic cracks in the semiconductor crystal structure. In the end, this leads to overheating and deterioration in the performance. It's important to note, however, that the base efficiency for this technology in commercial systems has not yet reached 20 percent Figure 1.

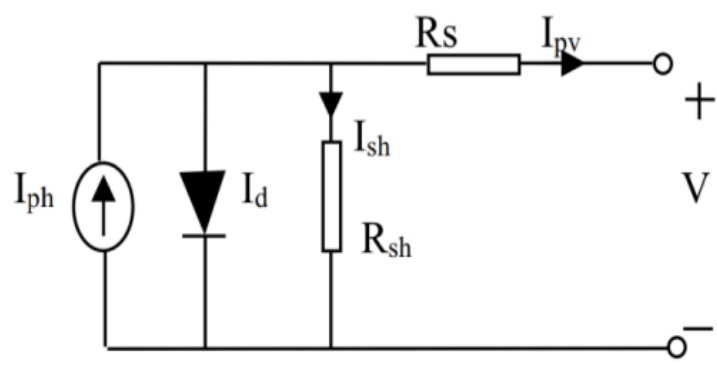

Figure 1: The solar cell is represented in a model
Using Kirchhoff's Laws, we obtain;

$$
I p v=I_{P h}-I_{d}-\frac{V+I R_{s}}{R_{s h}}
$$

Boost Converter is a powerful tool for converting In order to regulate the voltage value, the DC-DC boost converter is next in the chain. This voltage regulator uses a switch. Inductors are used to store energy, which is then used to regulate the output Figure 2 .

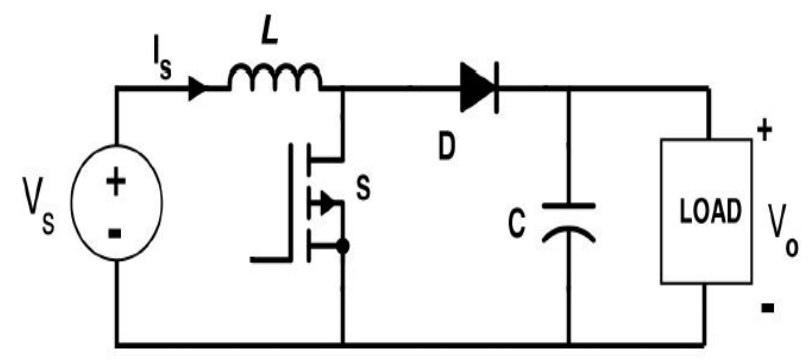

Figure 2: The input/output relationship for the converter is also included

Voltage Source (Vs), Inductor (L), Diode (D), Switching Device (S), Output Filter Capacitor (C), and Load Voltage (Vo). When comparing input and output, the expression is;

$$
V_{o}=\frac{V_{s}}{1-k}
$$

$\mathrm{S}$ is controlled by a PWM with a duty cycle of $\mathrm{k}$, which is the duty cycle.

As the switch on and off times are changed, the energy stored in the inductor is also altered. So the output voltage level can be more precisely controlled. The output voltage, on the other hand, is always higher than the input voltage, and cannot be lowered by design as a result. As a result, the output is identical to input when the duty cycle is zero. If you want to use the converter outside of its specified voltage range, you will need to change the component values or design.

schematic for an SPWM

As a result of comparing the carrier's duty cycle to that of the sine wave's slope, PWM is created Figure 3. 
International Journal of Innovative Research In Engineering \& Management (IJIREM)

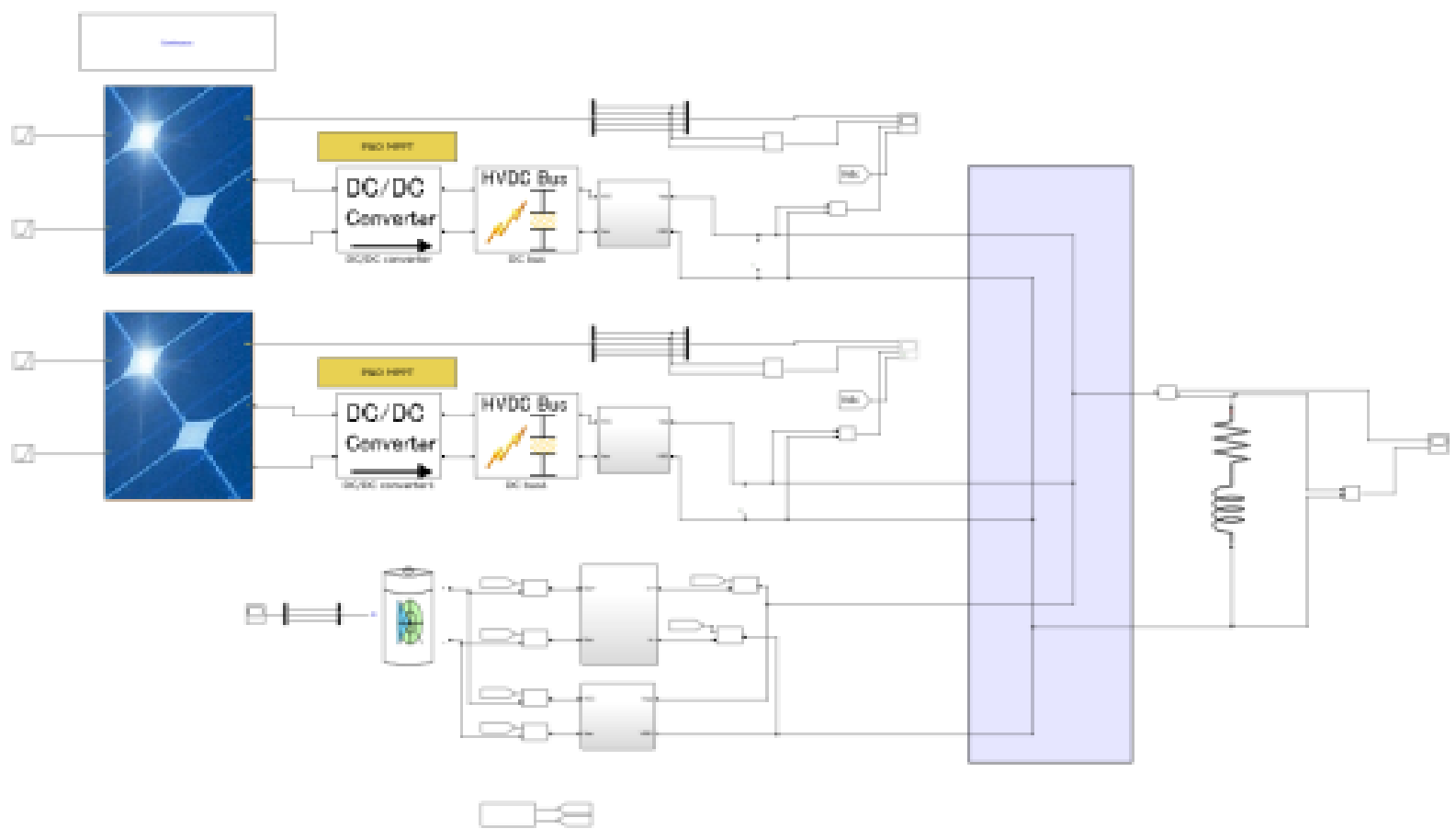

Figure 3: Blue indicates the main simulation block that connects multiple sources to the same DC bus

An MPPT or maximum power point tracker (MPPT) block receives the PV panel array system's output. As a result, the perturb and observe algorithm is used to maximize the panel's output. As part of MPPT, a DC-DC boost converter is used in conjunction with an HVDC filter capacitor. If you want a $100 \mathrm{~V}$ fixed voltage on the DC bus, you'll need a buck converter that follows it. Sources can share loads by adjusting the voltage of individual sources, which controls how much load is handled by each unit Figure 4.

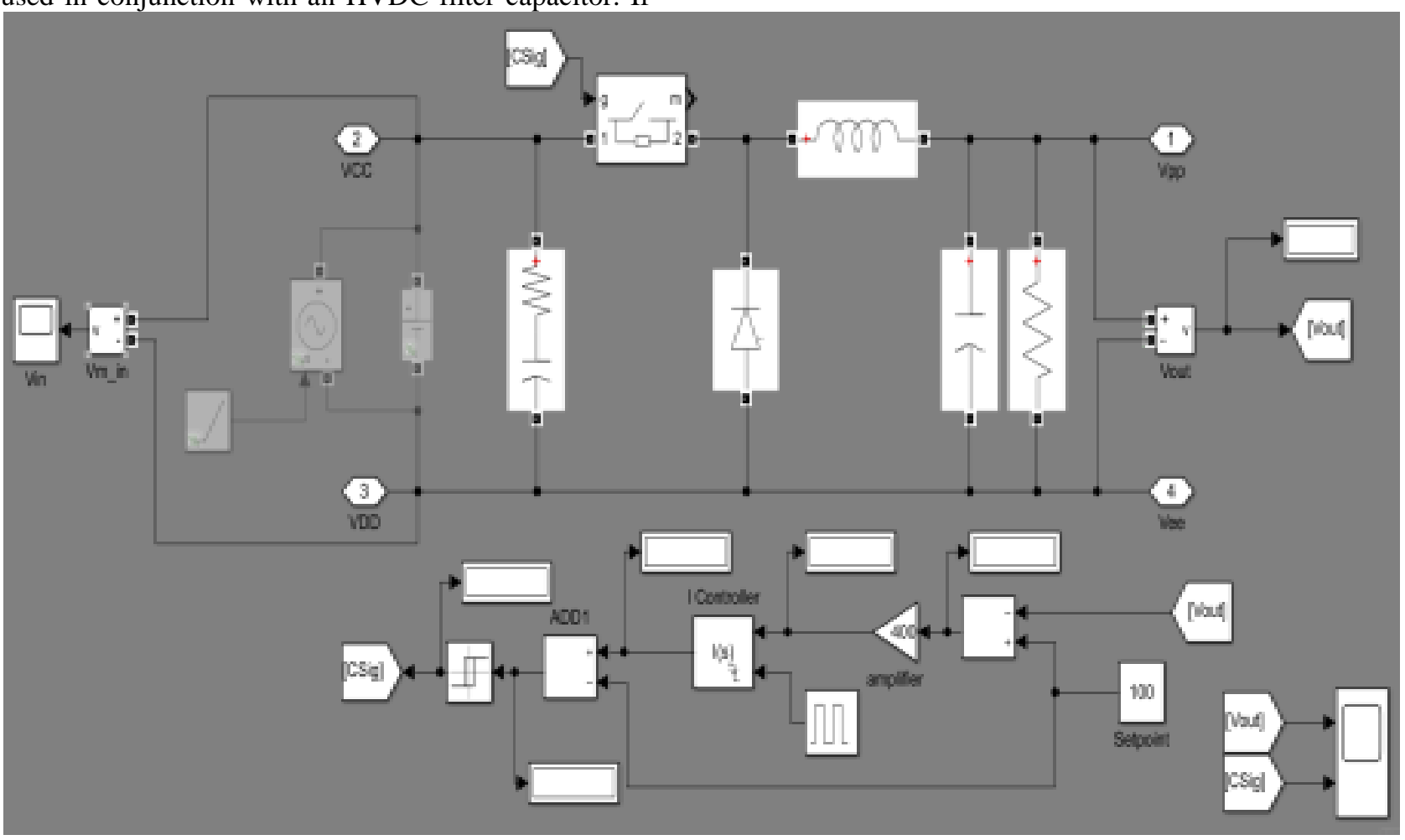

Figure 4: Buck converter internal design

The switch's control frequency is $10 \mathrm{kHz}$, and the integral controller gain is 40000 . It is set at a constant 100 volts. In this case, the battery is used to store the energy when the load is low and to use it when the demand is high. 160V nominal rating for the battery. But in order to charge it, you'll need a higher voltage of 200 volts. The boost converter is used to obtain higher charging voltage, and the buck converter is used to reduce the voltage back to DC- 
bus level of $100 \mathrm{~V}$ when the battery supplies energy. In order to prevent an irregular flow of electricity, switches and signal builder blocks are used. Battery can only charge or discharge at a time. In order to charge the battery, the boost converter block is set to produce $200 \mathrm{~V}$ Figure 5

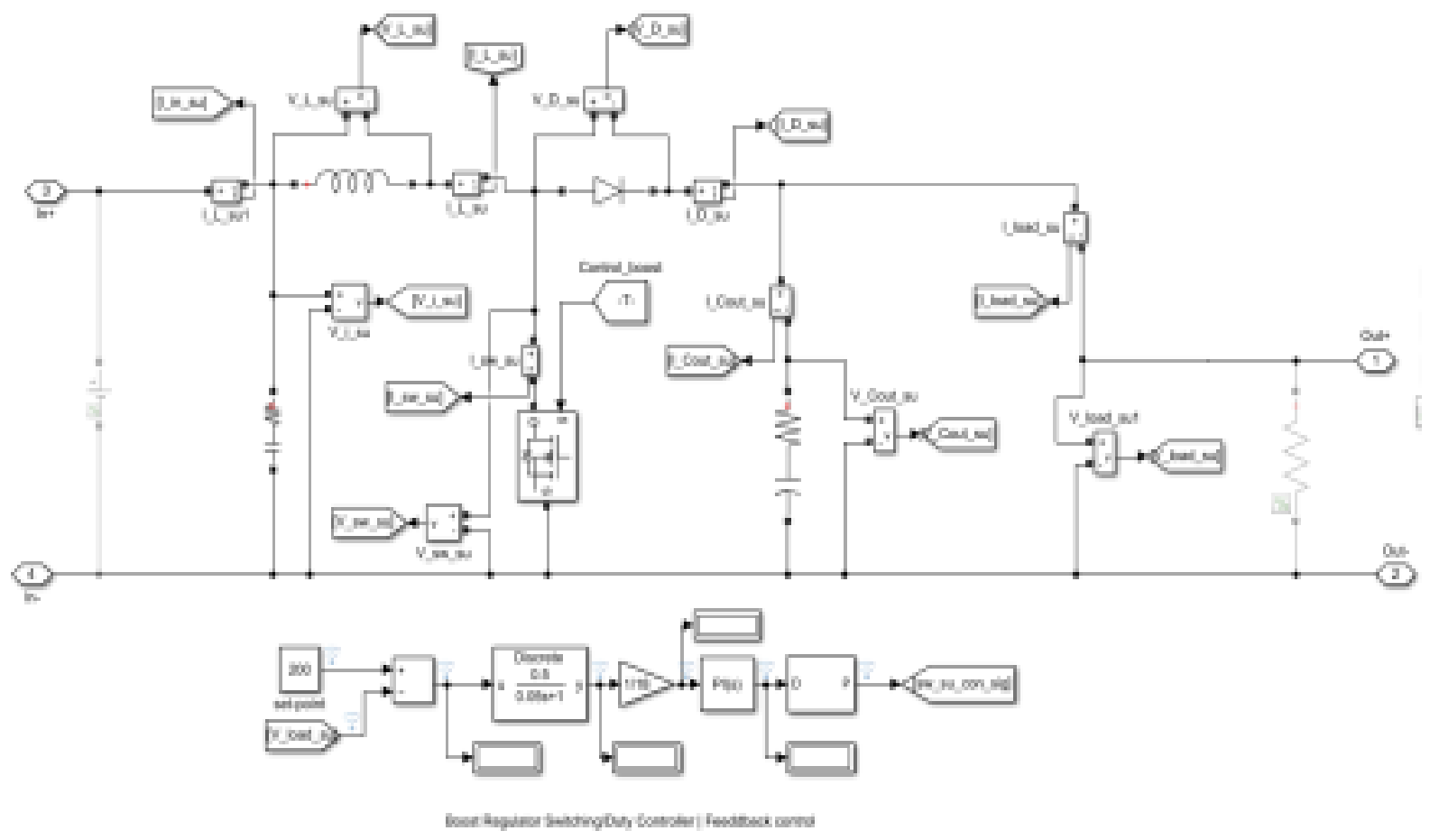

Figure 5: Design of Boost Converter

\section{RESULTS}

On one hand, the simulation sought to determine the behavior of two photovoltaic sources synchronized on a common DC-link, while on the other hand it examined a distributed control architecture with multiple loads [inverters].
On the following pages, you will find snapshots of data from the scope.

- An SPV unit's output is: From top to bottom: PV array output, PV array output power, final output voltage at the DC-link, and MPPT HVDC block output voltage Figure 6 \& Figure 7.

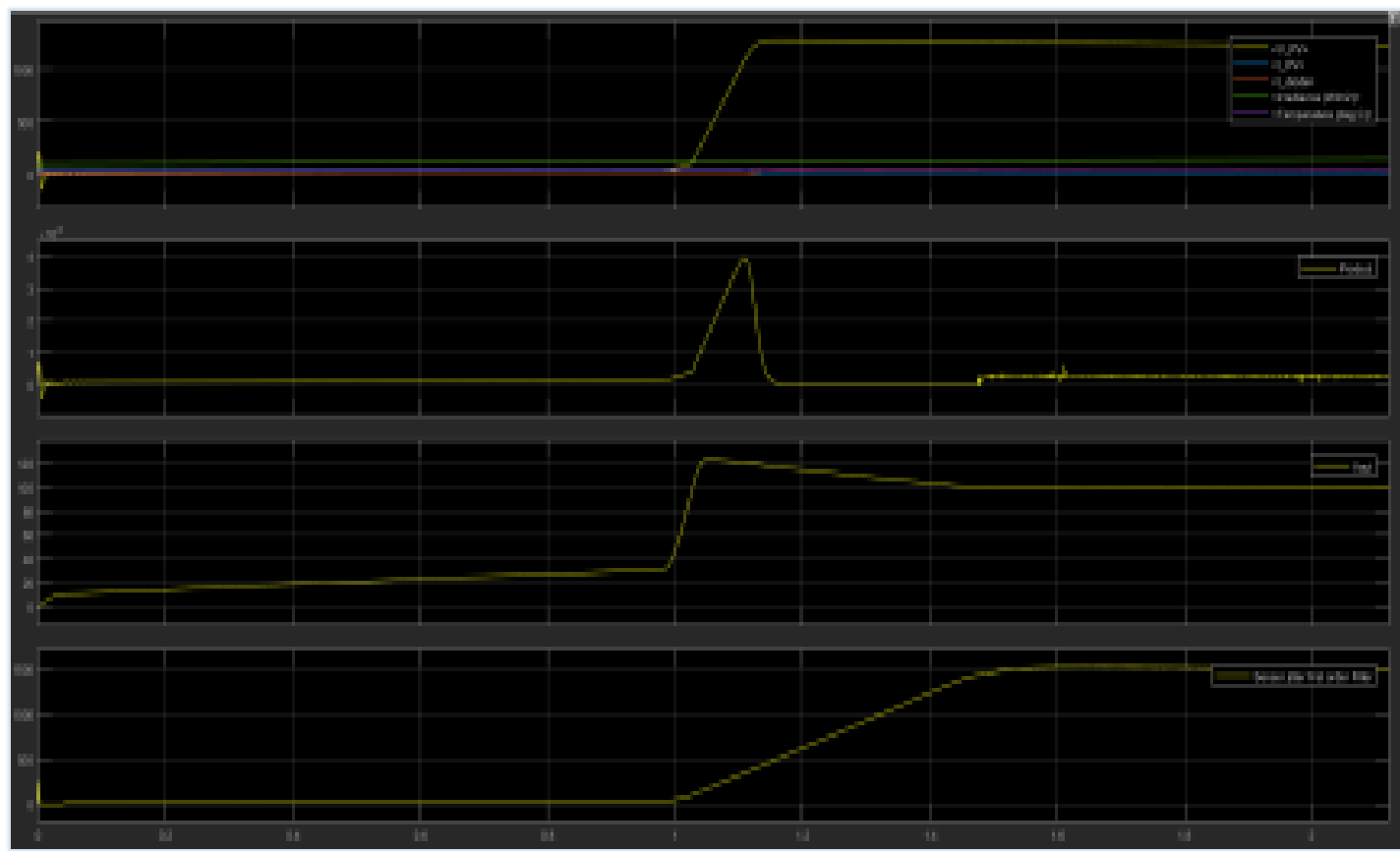

Figure 6: Output of a single SPV 


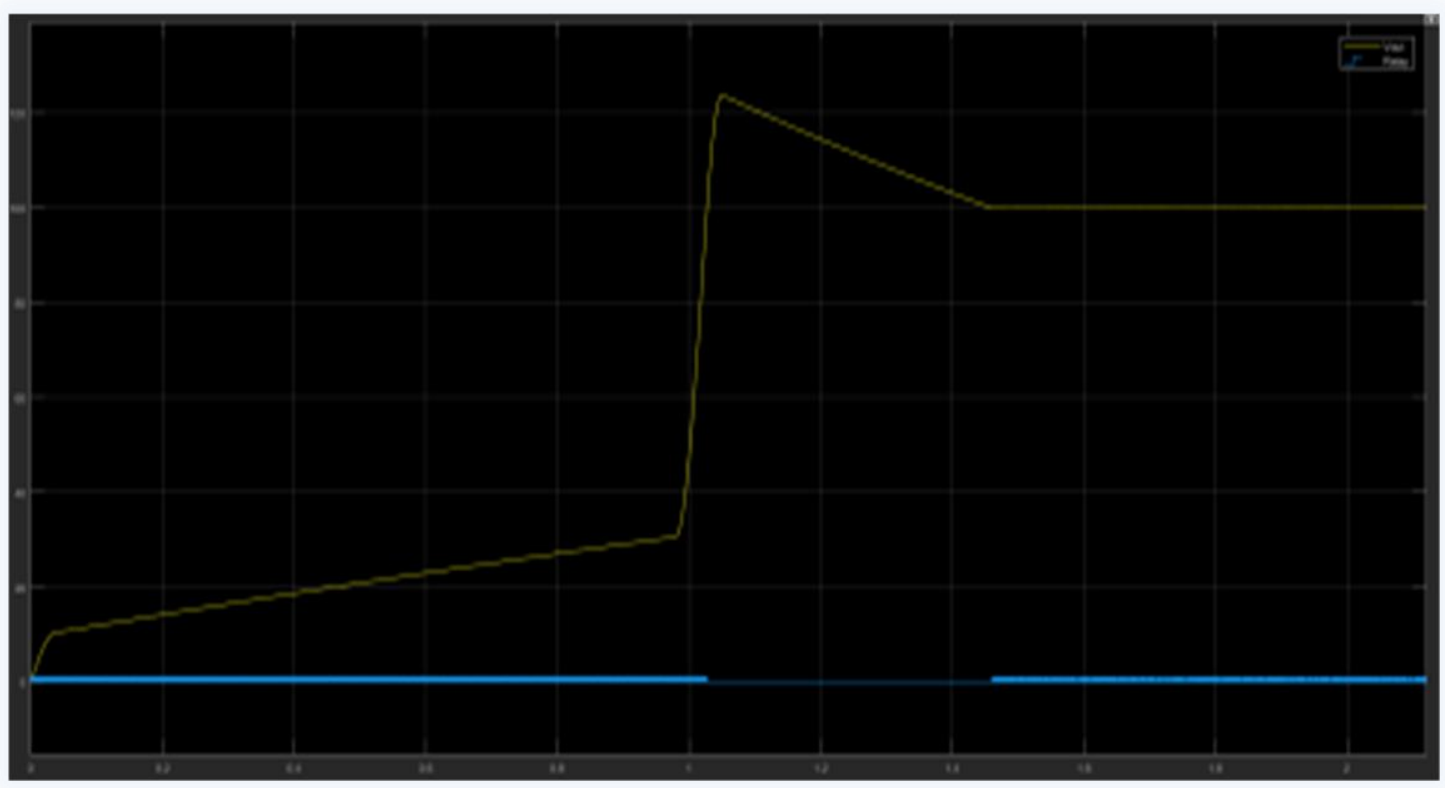

Figure 7: Output of the buck converter

- A $100 \mathrm{~V}$ output is eventually reached by the buck converter. Buck converter switching waveform is shown in blue. To compensate for the overshoot, the switch is turned off between 1 and 1.4.
- Each of the battery's characteristics is described in the legend. When the battery discharging system is turned on, a blue spike appears. As the wires have resistance, this spike will not occur in real life, but it will in MATLAB since connectors are not resistive Figure 8.

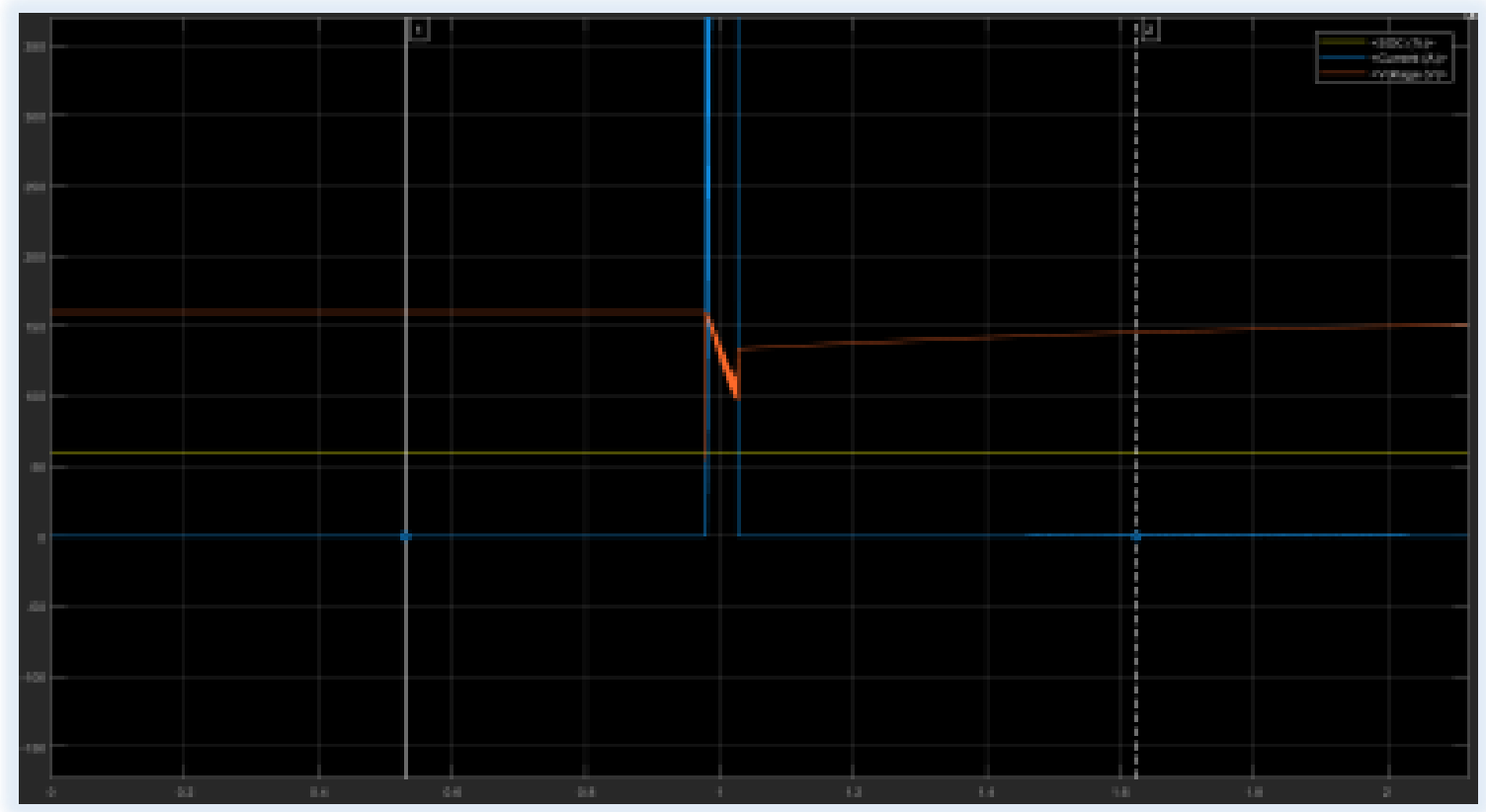

Figure 8: Battery characteristics

- Second buck converter voltage waveform for the second source is shown on the next picture, which shows a battery buck converter that supplies $10 \mathrm{~A}$ at $100 \mathrm{~V}$ to the DC-link Figure $9 \&$ Figure 10. 


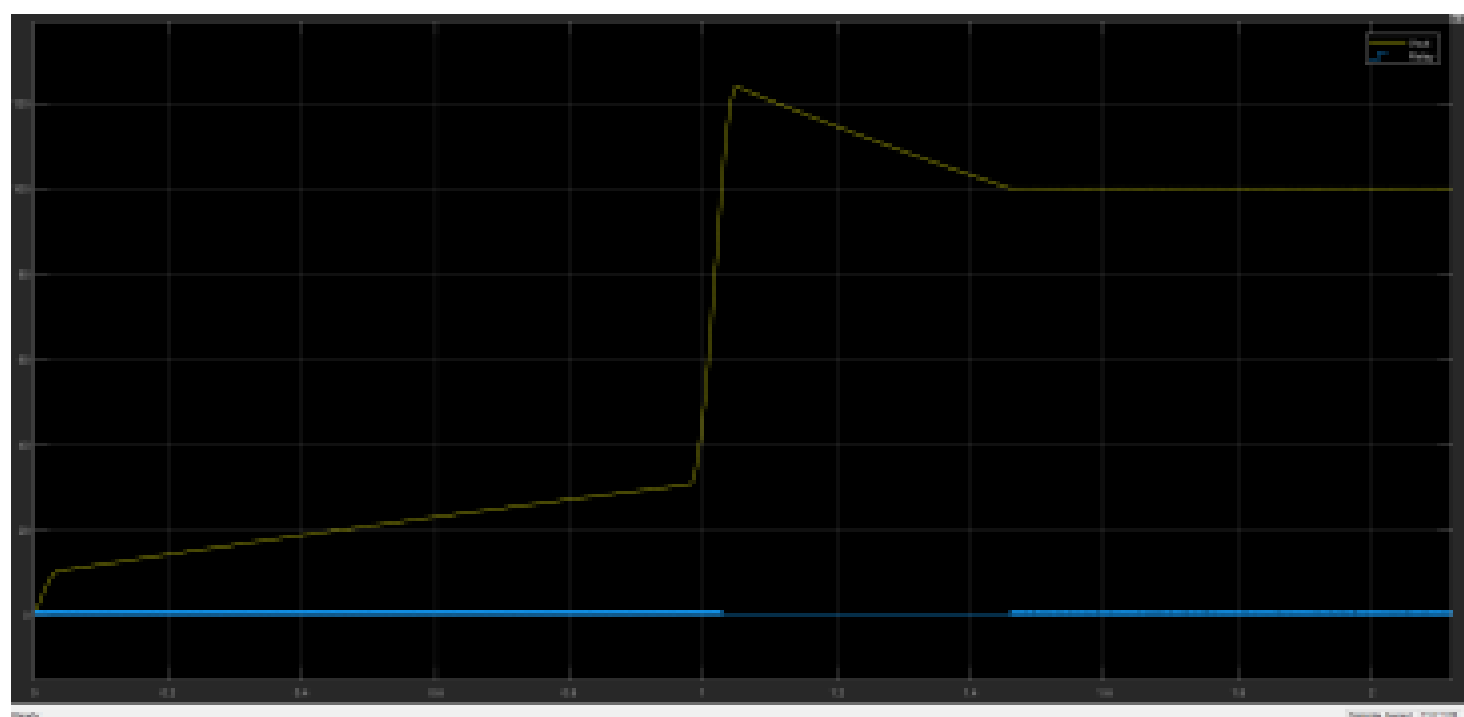

Figure 9: Voltage Waveform

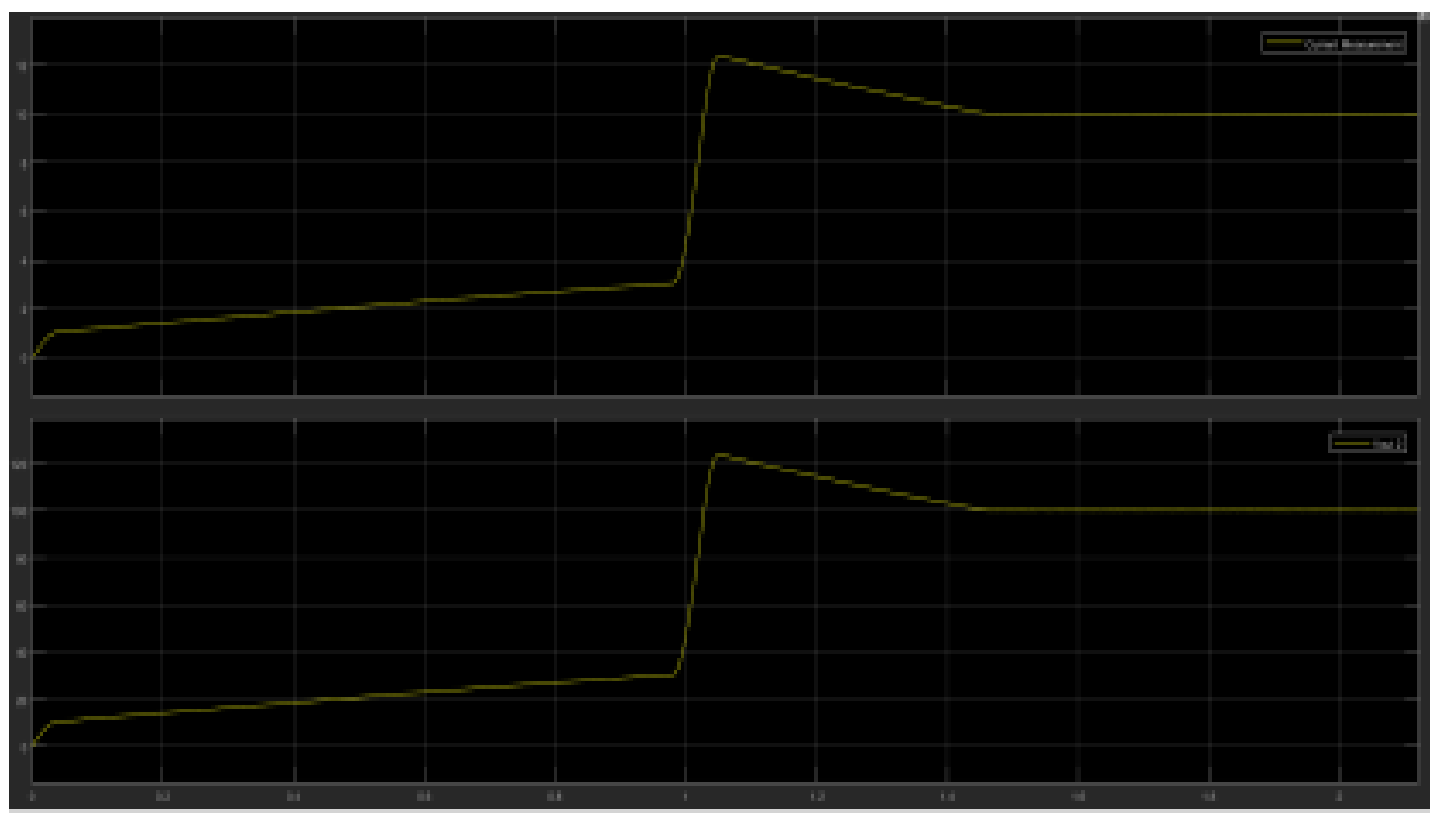

Figure 10: Buck Converter Output

\section{CONCLUSION}

The primary goal of this research was to design a micro grid system with multiple sources and a decentralized control architecture, and it was accomplished. According to the results, the behavior of the decentralized control is easier to manage because coordination between different components in a connected structure is not a major concern.

\section{CONFLICTS OF INTEREST}

The authors declare that they have no conflicts of interest.

\section{REFERENCES}

[1] U.S. Energy Information Administration. Energy Information Administration. International Energy Outlook 2016; U.S. Energy Information Administration: Washington, DC, USA, 2016; Volume 484, ISBN 2025866135 .
[2] International Energy Agency. World Energy Investment Outlook; International Energy Agency: Paris, France, 2014; Volume 23, p. 329.

[3] REN21. Renewables 2018 Global Status Report; REN21 Publications: Paris, France, 2018; ISBN 9783981891133

[4] Aris L. Dimeas, Nikos D. Hatziargyriou, "Operation of a Multi-agent System for Microgrid Control", Power Systems, IEEE Transaction on, vol. 20, no. 3, pp. 1447-1455, 2005.

[5] Palak Jain, Satish. J. Ranade, "Capacity Discovery in Customer-Driven Microgrids," Power Symposium, Proc. of the 41th Annual North American, Mississippi State University, Oct. 2009.

[6] M. Pipattanasomporn, H. Feroze, S. Rahman, "Multi-Agent systems in a distributed smart grid: design and implementation.

[7] J. Oyarzabal, J. Jimeno, J. Ruela et al., "Agent-based Microgrid Management System," Future Power Systems, International Conference on, Amsterdam, Nov. 2005, pp. 16.

[8] CIGRÉ 635-Microgrids 1 Engineering, Economics, \& Experience; WG C6.22; CIGRÉ: Paris, France, 2015; ISBN 9782858733385 . 
[9] Soshinskaya, M.; Crijns-Graus,W.H.J.; Guerrero, J.M.; Vasquez, J.C. Microgrids: Experiences, barriers and success factors. Renew. Sustain. Energy Rev. 2014, 40, 659-672.

[10] Parhizi, S.; Lotfi, H.; Khodaei, A.; Bahramirad, S. State of the art in research on microgrids: A review. IEEE Access 2015, 3, 890-925. [CrossRef]

[11] Comodi, G.; Giantomassi, A.; Severini, M.; Squartini, S.; Ferracuti, F.; Fonti, A.; NardiCesarini, D.; Morodo, M.;
Polonara, F. Multi-apartment residential microgrid with electrical and thermal storage devices.

[12] Hatziargyriou, N. Microgrids: Architectures and Control; Wiley: Sussex, UK, 2013; ISBN 9781118720677.

[13] Khodaei, A.; Bahramirad, S.; Shahidehpour, M. Microgrid Planning Under Uncertainty. IEEE Trans. Power Syst. 2014 